\title{
Integrated control of Chagas disease for its elimination as public health problem - A Review
}

\author{
Sergio Sosa-Estani ${ }^{1,2} /{ }^{+}$, Elsa Leonor Segura ${ }^{1,2}$ \\ 'Instituto Nacional de Parasitología Dr Mario Fatala Chaben, Ministerio de Salud de la Nación, Buenos Aires, Argentina \\ ${ }^{2}$ Consejo Nacional de Investigaciones Científicas y Técnicas de Argentina, Buenos Aires, Argentina
}

Chagas disease or American trypanosomiasis is, together with geohelminths, the neglected disease that causes more loss of years of healthy life due to disability in Latin America. Chagas disease, as determined by the factors and determinants, shows that different contexts require different actions, preventing new cases or reducing the burden of disease. Control strategies must combine two general courses of action including prevention of transmission to prevent the occurrence of new cases (these measures are cost effective), as well as opportune diagnosis and treatment of infected individuals in order to prevent the clinical evolution of the disease and to allow them to recuperate their health. All actions should be implemented as fully as possible and with an integrated way, to maximise the impact. Chagas disease cannot be eradicated due because of the demonstrated existence of infected wild triatomines in permanent contact with domestic cycles and it contributes to the occurrence of at least few new cases. However, it is possible to interrupt the transmission of Trypanosoma cruzi in a large territory and to eliminate Chagas disease as a public health problem with a dramatic reduction of burden of the disease.

Key words: Chagas disease - Trypanosoma cruzi - prevention - control - public health - neglected disease

Chagas disease or American trypanosomiasis is, together with geohelminths, the neglected disease that causes more loss of years of healthy life due to disability in Latin America (Hotez et al. 2008).

Trypanosoma cruzi, its causative agent, can be transmitted by different ways: vector (through triatomines), blood (through uncontrolled blood transfusions and organ donations, congenitally, by sharing needles among intravenous drug users, exceptionally through laboratory accidents or surgical interventions with contaminated material) or oral (through food contaminated with faeces of infected vectors) (WHO 2002). The endemic area for vector-borne transmission extends from the southern United States of America (USA) to southern Argentina and Chile. Blood transmission can occur anywhere in the world where people are infected and there are no screening strategies for blood or organ donors. The oral way has been described mainly, but not exclusively, in the Amazon Region.

The disease affects between seven-eight million people in the Americas (OPS 2006). It is estimated that between $20-30 \%$ of patients with infection will present some kind of clinical evidence (cardiac, digestive, neurological or mixed) (WHO 2002).

\section{doi: 10.1590/0074-02760140408}

The text of this paper was used in part of chapters Epidemiología de la enfermedad en países endémicos, Enfermedad de Chagas -

Un enfoque práctico basado en la investigación médica, Panamericana Published, and Chagas disease, Infectious diseases and public health, Elsevier, in press.

+ Corresponding author: ssosa@msal.gov.ar

Received 31 October 2014

Accepted 2 April 2015
The Pan American Health Organization (PAHO) has reviewed possibilities of different levels of control for several neglected diseases related with poverty. These diseases include Chagas disease among others like lymphatic filariasis, onchocerciasis, schistosomiasis, trachoma, soil-transmitted helminth, leprosy, congenital syphilis, among others. The discussion makes differences between different level of geographical distribution such as sub national, country or regional levels and levels of control possible to reach. Other discussion is which levels of control could be reached like eradication: as global and permanent incidence of zero due to deliberate actions, suspension of surveillance and control, control, reducing the burden of disease at certain levels of magnitude that would be defined, and elimination, zero incidence in a geographical area due to deliberate actions, requiring continued surveillance and control measures (OPS 2009a).

The aim of this review is to describe the current status of Chagas disease control and the goal. We reviewed the evidence supporting the use of different strategies for control of Chagas disease. In this regard, a MEDLINE search was conducted, using the term "Chagas disease" with the subheadings, "control", "diagnosis," "prognosis," "treatment". No restrictions regarding year, language or country of publication were applied. Recent guidelines as well as ongoing and unpublished studies were also identified by consulting researchers and experts in the field.

\section{Epidemiologic components}

Modes of transmission and distribution factors Various scenarios should be considered when trying to understand the transmission dynamics of T. cruzi. The emergence of transmission of T. cruzi and the maintenance cycle of Chagas disease involve a diversity of elements. There is diversity in vector species, their be- 
haviours and biotopes (Fig. 1), there is diversity in the lineage of the parasite (Zingales et al. 2012), diversity in its wild and human hosts, in their potential susceptibility to infection and in their response and there is also diversity in the behaviours of the people infected and their social environment, generating a variety of risk or protection scenarios for the various forms of transmission.

The conjunction of this diversity creates some specific scenarios that must be taken into account when making a diagnosis of the situation and designing control strategies to prevent transmission or mitigate the existing damage.

Regarding the determinants related to the vector and its behaviour, we could consider scenarios where the main vector is exclusively domestic and introduced, as in the case of Rhodnius prolixus in Costa Rica, which could be eliminated (Hashimoto \& Schofield 2012). Scenarios in which the main vector is essentially domestic, but not exclusively (as it can be found in wild niches close to homes), with the consequent risk of the reintroduction of this and other species, as in the case of Triatoma infestans in the phytogeographic region of South America's Gran Chaco (constituted by geographical areas of Argentina, Bolivia and Paraguay) (Ceballos et al. 2011). Scenarios where the main vector is exclusively peridomestic in peridomestic and wild environments, as in the case of Triatoma dimidiata in Mexico, with the consequent difficulty of intervening to control its reproduction niche (Pacheco-Tucuch et al. 2012).

A different context is that of vector and oral transmission, which is mainly associated with the presence of infected vectors that can contaminate food (ShikanaiYasuda \& Carvalho 2012).

The conditions for food contamination with infected vectors in the Amazon Region to become a risk of oral transmission of $T$. cruzi are partly the jungle environment where the infected triatomines reproduce and survive and which forms the domestic landscape in which the inhabitants of that region prepare and consume their food (OPS 2009b).

T. cruzi is genetically diverse and understanding the population structure of this parasite is critical due to its association with transmission and disease cycles. Currently, T. cruzi is divided into six discrete typing units (DTUs), TcI-TcVI, with different prevalence according to the geographic region. DTUs TcI are prevalent in domestic settings, which have a higher risk for vector transmission, in northern South America and Central America, while DTUs TcII, V and VI are prevalent in southern South America (Zingales et al. 2012). The authors that made this description concluded that major advances in the understanding of the pathogenicity and epidemiologic characteristics of these parasites can be expected in the next decade from the comparative analysis of the genomes of several DTU strains (Zingales et al. 2012). However, potential differences with respect to the performance of diagnostic methods and therapeutic responses must be considered.

To all the above, we must add the prominent role played by social factors, which determine the behaviour of the people and their living conditions. Unfavourable geographical and political phenomena that prevent peo-

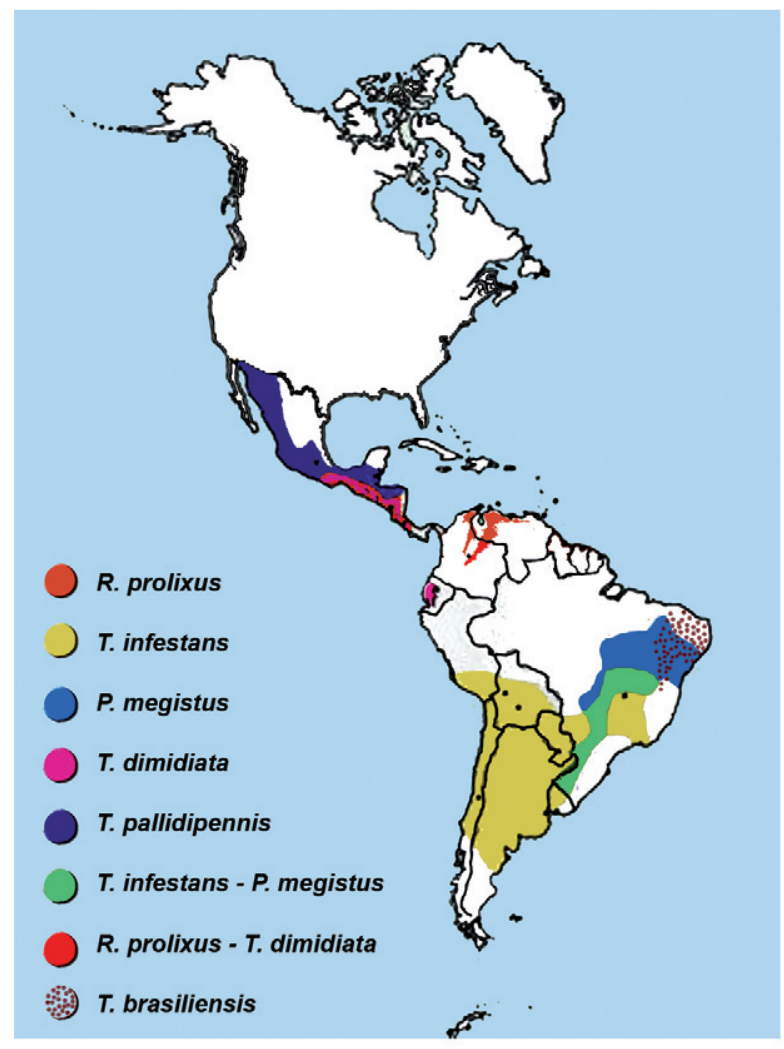

Fig. 1: distribution of main species of Trypanosoma cruzi transmission vectors. This map was provided by Dr R Salvatella, Pan American Health Organization, Uruguay.

ple from living under decent conditions play a fundamental role in determining the risk of vector infestation in human habitats and the consequent risk of becoming infected through these routes. Thus, people's behaviour can create situations of risk or protection. For example, a study conducted in 1984 in South America's Gran Chaco region (Termas de Río Hondo, Santiago del Estero, Argentina), in which there was no vector control or recent insecticide treatments at the time of the study, analysed the factors associated with the presence of infection in children. The combination of the presence of hiding places for vectors within the houses (cracked walls and thatched roofs), having more than two dogs or cats, animals sleeping in the bedrooms and peridomestic structures (sheds, pens etc.) close to the bedrooms were associated with an infection rate in children between five-14 years of age of $36.4 \%$, while families in the same area where these same factors were absent had infection rates in children of the same age of $7.7 \%$. Given that no vector control with insecticides was a factor in both cases, the presence of environmental and behavioural factors posed a significant risk for acquiring the infection through vector transmission (Chuit et al. 2001).

The routes of transmission by blood are not conditioned by environmental factors, as in the case of vector and oral transmission, but almost exclusively by sociodemographic determinants associated with the migration of people. The risk of transmission by blood exists where 
there are infected persons, the main factor to consider when planning public health interventions being the amount of infected people in a locality, whether or not the area suffers from triatomine infestation and vector transmission. Thus, in areas where no conditions exist for vector transmission (absence of vectors), but where there is intense immigration of people from an area with vector transmission, there may be a risk of transmission by blood that requires the implementation of measures to control transmission through these routes, such as screening of blood and organ donors and monitoring of pregnant women and newborns from women infected with T. cruzi (Mallimaci et al. 2001, 2010).

\section{Prevention and control activities}

Control strategies must combine two general courses of action including prevention of transmission to prevent the occurrence of new cases (these measures are cost effective) (Vazquez-Prokopec et al. 2009), as well as opportune diagnosis and treatment of infected individuals in order to allow them to recuperate their health, when possible, to provide comfort to the patient and to their family and community and to break the chain of transmission by blood by reducing the amount of parasites in donors and mothers (Sosa-Estani et al. 2012). It must be noted that reducing the burden of the disease on society would lead to a consequent reduction in health-care spending (Lee et al. 2013).

Evolution of intervention strategies for control - Intervention strategies for the control of insect vectors were designed and implemented in the 50s and 60s and for the control of transmission by transfusion in the $60 \mathrm{~s}$ and $70 \mathrm{~s}$, respectively. The pioneers in implementing these strategies were Venezuela, Brazil and Argentina (OPS 2002). Strategies for control of congenital transmission began to be implemented in the 80s; while it still cannot be prevented, it can be controlled by early diagnosis and timely treatment of children with congenital infection (Blanco et al. 2000).

The chronology described above occurred in several countries in the Americas, with different times of implementation and different levels of efficacy. There also countries without formally established programs for controlling the transmission of T. cruzi. Since the end of the $90 \mathrm{~s}$, other regions such as North America, Europe and Australia have launched research projects and some countries have implemented programs for controlling a specific route of transmission (the only one in the area), such as universal screening of blood donors in the USA, or, as in Spain, of donors coming from regions of endemic vector transmission (WHO 2002).

The practices for taking care of people infected with this disease have evolved from the time when Carlos Chagas first described it; they currently include health team interventions and care guides (MS 2012a), which have been implemented in very different ways in different endemic countries. Only in the mid-90s some countries started to implement the practice of detecting infected children and providing them with etiological treatment as part of a number of strategic actions for controlling the disease (OPS 2002). This is now part of the protocol used by endemic countries, which have institutional control programs through which they certify the interruption of vector transmission by demonstrating the absence of infection in children less than five years of age. A certification of the interruption of transmission is complemented by the absence of the vector, low domestic infestation $(<$ $1 \%$ ) and no reported cases of acute vector Chagas, among other indicators. The status reached of interruption is characterised by a sustained surveillance after intensive activities of control of vectors (OPS 2002). A review conclude that the combination of spray activities for control of focus of infestation and the community participation should become a strategic component of Chagas disease surveillance (Abad-Franch et al. 2011).

The activities to prevent transmission of $T$. cruzi by transfusion are based on the implementation of blood bank control. These strategies started in 70 s by 2005 did not reached an adequate rate of implementation in Latin America (Schmunis \& Cruz 2005), but it was improved during last decade and more recently these programs were implemented in nonendemic countries (RequenaMéndez et al. 2014). Fig. 2 shows the progress of the interruption of vector transmission in the countries of the Americas. Only recently has emphasis been placed on the comprehensive care of infected people in any stage of the infection (MS 2012b) as essential to the goal of eliminating Chagas disease as a public health problem (Sosa-Estani 2012, Sosa-Estani et al. 2012).

Achieved effect - The sum of the measures for prevention of transmission have had different a different effect depending on the possibility of implementing interventions. The factors on which this depends include: (i) the political and technical decision to implement the strategies with sufficient evidence of efficacy [some examples that demonstrate the feasibility of the various factors described in (i) are the success in interrupting vector and blood transmission, with total or partial geographic coverage in some countries, such as Argentina, Brazil, Chile, Uruguay and some others in Central America (Fig. 2)], (ii) the complexity of the scenario in which the intervention takes place [examples of (ii) could correspond to specific sub-regions, such as the complexity of determinants in the Amazon Region that cause outbreaks of oral transmission] and (iii) the lack of tools or strategies or insufficient evidence of efficacy [examples of (iii) could be special situations such as the occurrence of pockets of triatomines resistant to insecticides approved for vector control] (Germano et al. 2012).

The measures implemented in recent decades have had an effect, as confirmed by the World Health Organization (WHO) when describing that the number of infected people decreased from 30 million in 1990 to 15 million in March 2006 (OPS 2006). However, these estimates may have methodological shortcomings in their calculations and may not allow us to make an accurate assessment due to their high potential margin of error. It is also clear that the various control measures that have been systematically carried out since the formal establishment of control programs for Chagas in endemic countries at the start of the $60 \mathrm{~s}$ have served to prevent new cases in many countries in the Americas. However, the diversity of socioepidemiological scenarios and im- 


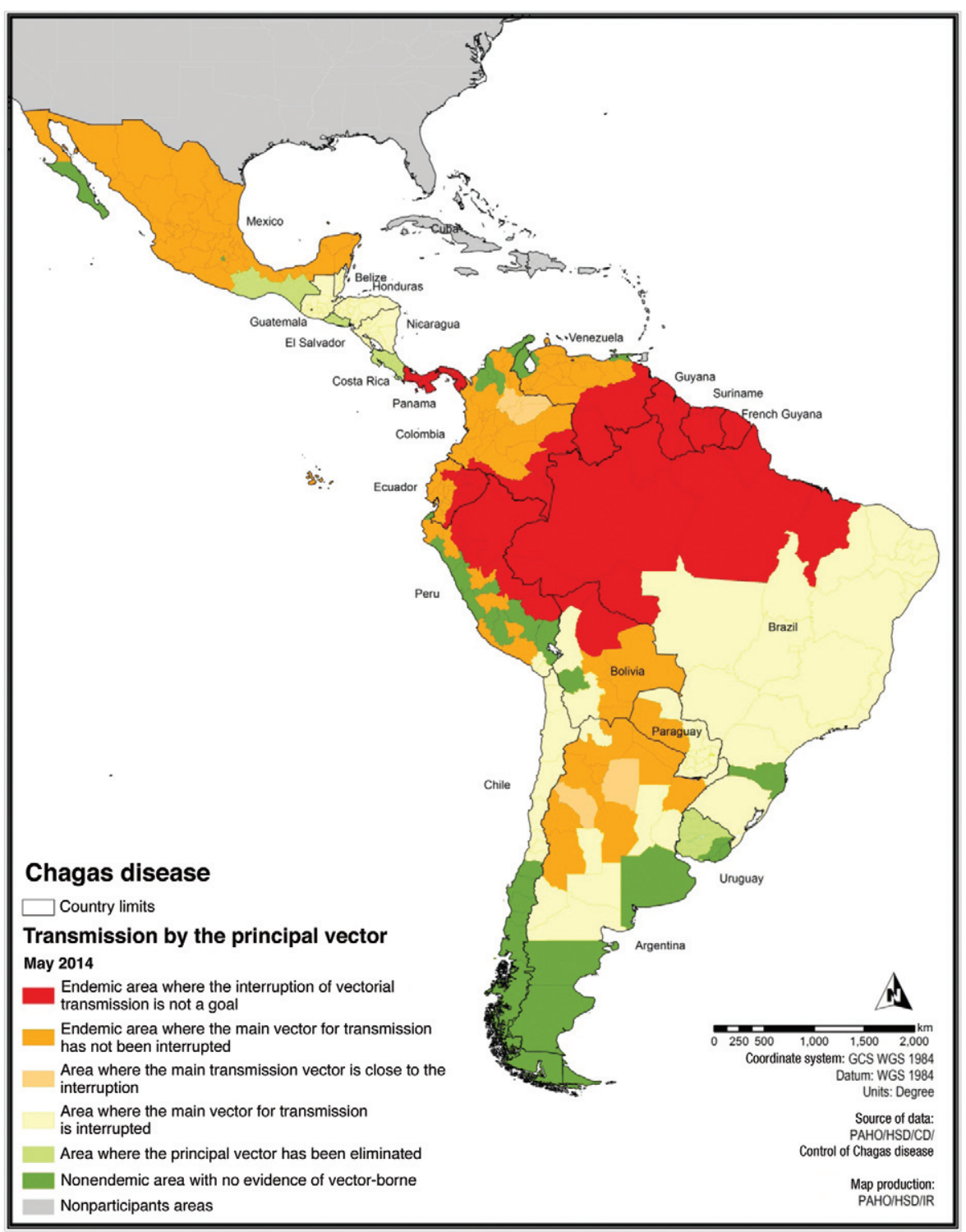

Fig. 2: status control vector transmission in the Americas. Source: Pan American Health Organization (paho.org/hq/index.php?option=com_t opics\&view=article\&id=10\&Itemid=40743).

plementation status of control programs has meant that while the main routes of transmission of public health interest (vector and blood) have been successfully interrupted in some regions, new cases involving these routes of transmission are still occurring in other regions.

The control of vector and blood transmission of $T$. cruzi clearly improved the transmission profile in Latin America. Some specific examples of these progress in different geographical dimension are the control in the state of São Paulo, Brazil, which started by 70s with continuous surveillance and high impact avoiding new cases by vector transmission for several decades (Carvalho et al. 2011). On the other hand in Central America (Guatemala, El Salvador, Honduras and Nicaragua) an example of interaction between international cooperation by the Japan International Cooperation Agency, Japan, official control programs of the countries involved and community organised could reach a high level of control of transmission. This model highlighted for the success: the knowledge for what actions should be taken to control the disease, the competence to obtain resources and capacity to implement control actions, the channels for the institutional network and infrastructure and the control of the technical and administrative management (Hanada \& Hashimoto 2014).

A very important issue to warranty the success of the Chagas disease programs is to implement evaluations programs of each activity, control quality, to monitoring its efficacy. These aspects were recently reviewed by a $\mathrm{PAHO} / \mathrm{WHO}$ group of experts and in addition were discussed that subjects involving sustainability, coverage, financing and quality of the program must be taken into account in each evaluation. 
Also it is necessary to offer process such as social, administrative and political issues involving an official declaration of disease elimination, considering the possible positive and negative points that can arise from this declaration taking into account gaps and needs for this goal. Some examples of the new scenario and the role of different actors are the recent constitution of the Federation of People Affected for Chagas disease (findechagas. $\mathrm{com} /$ ), the coalitions of nongovernmental organisations (NGOs) (web.mundosano.org/novedades/mundo-sanohoy/lanzan-una-coalicion-global-para-luchar-contra-laenfermedad-de-chagas/) in same case with the industry (unitingtocombatntds.org/resource/london-declaration), forum for research (dndial.org/es/doencas-negligenciadas/enfermedad-de-chagas/plataformachagas.html), the constitution or revision of a national plan with political support and international declaration of WHO Assembly.

Beyond the measurement of progress, several questions still remain, which can only be answered by further scientific research. At present, there is the need of designing and implementing a quality control system for the supply of domestic insecticides and for making accurate estimates of the effect of control measures on the incidence of new infections.

Considering the response of health systems to the reemergence of another infection caused by insects, dengue, it is surprising how fast they reacted, despite the fact that several programs for control of vector-borne diseases have started to be dissolved. In some regions of Latin America, this fast response was made possible by the strong influence of the control initiatives carried out by the PAHO of the WHO. Although we cannot quantify this influence, it can be said that it is a cultural influence generated by the initiatives. The case of the reemergence of the dengue virus and that of the emergence of the chikungunya virus, both transmitted by the Aedes genus, calls into question whether it is not time to strengthen the control programs and the scientific and technical training of the members of those programs in order to make them more effective and less costly in the context of the current challenges.

Having achieved the desired effect of interrupting the transmission of a disease, a major challenge is to achieve sustainable control measures to prevent a reestablishment of transmission, as happened with dengue and malaria in the Americas (Dick et al. 2012). Some of the current strategies aimed to achieve sustainability involve empowering local governments and promoting community mobilisation and participation through organised communities and NGOs.

The establishment of integrated programs constructed collectively allows proposing strategies that address as many determinants as possible for the control of Chagas disease. As an example, the recently revised National Program for Control of Chagas disease in Argentina, implemented between 2010-2016, consists of five strategic lines: (i) strategies for the prevention and control of vector transmission (vector control and surveillance, resistance monitoring, improvement of the environment - domestic and peridomestic), (ii) strategies for the prevention and control of nonvector transmission, particularly of transmission by blood, (iii) strategies for the control of congenital infection, (iv) strategies for the control of acute and chronic infection in carriers of $T$. cruzi and (v) general and transversal strategies for the whole program including strengthening of the political dimension, strengthening of the resources of the national and local programs for Chagas, social communication and community participation, assessment and monitoring of the program (MS 2012b).

These nationwide programs should consider particular situations, mainly related to vulnerable communities, such as care in indigenous communities where the perception and acceptability of the strategies should be approached with particular caution. This based on the evidence of the failure of interventions in these communities due to several factors, one of them being the use of standard procedures which in these populations may cause a kind of culture shock (Sosa-Estani et al. 2009a, Dell'arciprete et al. 2014).

In 2010, the WHO estimated the existence of seveneight million people infected with $T$. cruzi distributed throughout the world. The region of the Americas, particularly Latin America, where those with the highest proportion of infected people, being endemic areas for vector transmission the most efficient type of transmission. However, the phenomenon of human migration has created scenarios in need of attention in other regions of the world such as Europe, Japan and Australia, mainly with respect to the diagnosis and treatment of infected people to prevent and control congenital transmission and transmission by contaminated blood (WHO 2013).

There is limited information about the effect of health care activities in infected people on the overall activities of prevention and control. However, two fundamental concepts must be taken into account, either with evidence or when suggesting a hypothesis. The first is the direct effect that timely cares with early interventions have on the quality of life of the patients, with the consequent reduction of the burden of the disease by preventing or stopping its progression (secondary and tertiary prevention) (Sosa-Estani et al. 2012). The second concept is that indicating a trypanocidal treatment, which has proven effective in eliminating or reducing the parasitic infection, modifies the population parasitaemia, with consequential benefits. These benefits may include changing the natural history of the disease by producing less severe clinical chronic forms and/or decreasing the influence of parasitaemia (Sosa-Estani et al. 2009b) as a determining factor in the occurrence of congenital transmission (Bua et al. 2012, Howard et al. 2014).

\section{Care of people and levels of prevention}

There are guidelines advising regarding management and care of people infected with T. cruzi. A precocious and adequate clinical management is required to all acute or chronic cases. A timely and adequate clinical, pharmacological and chirurgical management if necessary is essential. The specific treatment has to be considered currently among other therapies (WHO 2002). For instance, timely management of initial arrhythmia, heart failure or megaesophagus is fundamental to avoid 
or delay the appearance of severe and irreversible situations, according several longitudinal studies have demonstrated (Viotti et al. 2005, Rassi Jr et al. 2006).

A challenge to each health system is how to implement the activities to provide an adequate care of people infected. There is a diversity of system, but all of them must to warrant a care with quality. There is a consensus that most of patients can to be care in the primary health care level and to be included into the schedule of national control programs.

The role of etiological treatment for T. cruzi infection on several levels of prevention in public health The etiological treatment allows for actions on several levels of public health prevention. Previous studies provide evidences useful for applying health care strategies in control programs in several countries. When a high number of people can get diagnosis, treatment and cure, it generates a new scenario for the future reduction of the burden of the disease.

Primary prevention level - If the goal is to prevent the occurrence of new infections, etiological treatment could have an indirect effect when applied to children and young people. Curing children and women in reproductive age would prevent future events of congenital $T$. cruzi transmission (Sosa-Estani et al. 2009a, Fabbro et al. 2014). In addition, blood and organ donors would increase if infected people are treated. Unfortunately, the effectiveness of the etiological treatment with respect to these primary prevention indications remains unknown, although it can be assumed to be at least equal to the seronegativisation rates observed in some studies. Another strategy would be to obtain a feasible treatment for pregnant women, such as that used for human immunodeficiency virus (HIV) infection, to prevent congenital transmission during pregnancy. However, safe drugs are necessary for this strategy.

Etiological treatment in cases of accidents with material contaminated with parasites or with blood samples of patients infected with T. cruzi could also be considered as an indication for primary prevention. In fact, the treatment is not strictly prophylactic, as it is not possible to prevent infections, but the infection can be aborted immediately after the accident with a timely treatment and an appropriate concentration of specific drugs (Herwaldt 2001). Recent results show the benefit, in terms of primary prevention, of treating girls and women of childbearing age before pregnancy, preventing the congenital transmission of $T$. cruzi to children born afterwards (Sosa-Estani et al. 2009a, Fabbro et al. 2014).

Secondary prevention level - If prevention activities cannot prevent infection in children, curing infected children is still possible by prescribing etiological treatment (Cerisola 1977, Moya et al. 1985, Russomando et al. 1998, Sosa-Estani et al. 2009b, Bern 2011). In this regard, etiological treatment should be indicated when damages from cardiac or digestive disease are not strongly present in children. This is the best opportunity to get seronegativisation and avoid disease, thus preserving social, mental and physical health into adulthood (de Oliveira Jr et al. 2006, Villa et al. 2007).
National control programs have been implemented in more and more Latin-American countries since 1994. They consist of the screening of children populations as a regular strategy providing early diagnosis and treatment (Silveira 2002). The positive effect of curing infected children detected by serological screening must be assessed by taking into account the number of infected people, the transmission, evolution and burden of Chagas disease, so that it becomes possible to analyse the usefulness of serology as an indicator of action against the vector.

Another indication for etiological treatment in secondary prevention is to prevent the reactivation of a chronic infection. Immunosuppression due to the application of immunosuppressive therapies (Diez et al. 2007) or HIV/ acquired immune deficiency syndrome (Cordova et al. 2008) increases the risk of reactivation in patients with chronic infection. Even though the effectiveness of etiological treatment for the clinical control of reactivation episodes has been demonstrated, it is necessary to gather evidence as to whether preventive treatment is effective in patients with no signs of clinical reactivation and with abnormal immunological parameters (Nishioka 2000). In this regard, some protocols recommend treating organ donors infected with $T$. cruzi to reduce the risk of transmission by transplant (Altclas et al. 2005). In this case, treatment should be considered as a primary prevention action.

Tertiary prevention level - The use of etiological treatment against $T$. cruzi infection in order to reduce the negative effect of established disease is being evaluated using two randomised clinical trials for assessing its efficacy in patients with ongoing cardiac disease (Reyes \& Vallejo 2005, Riarte et al. 2005, Marin-Neto et al. 2008). These trials are appraising the efficacy of benznidazole for preventing the progression of cardiac disease.

Several observational studies have been published showing the effects of etiological treatment on patients infected with $T$. cruzi with respect to preventing the progression of chronic chagasic cardiomyopathy (Sosa-Estani et al. 2009b). These studies achieved quality of evidence type II and strength of recommendation B and C. The prognosis of patients with heart failure or advanced stages of chagasic cardiomyopathy is poor (Rassi Jr et al. 2006), but similar to that of other patients who develop heart failure. Since the disease is chronic and heart damage develops over decades, it is very important to recognise the factors that determine the progression of the disease in the early stages (Viotti et al. 2005). The evolution of knowledges addressed to the current scenario with a new paradigm regarding benefit of trypanocide treatment (Viotti et al. 2014). The etiological treatment should be considered as a protective factor in the model of the physiopathology of chagasic cardiomyopathy.

As mentioned above, the effectiveness of etiological treatment in the control of reactivation episodes has been proved, showing recovery from severe manifestations of reactivation such as meningoencephalitis, myocarditis, panniculitis etc. (Diez et al. 2007, Cordova et al. 2008).

Based on our current understanding of the disease, there is a consensus that every patient infected with $T$. cruzi must (children) or should be treated (adults). Treat- 


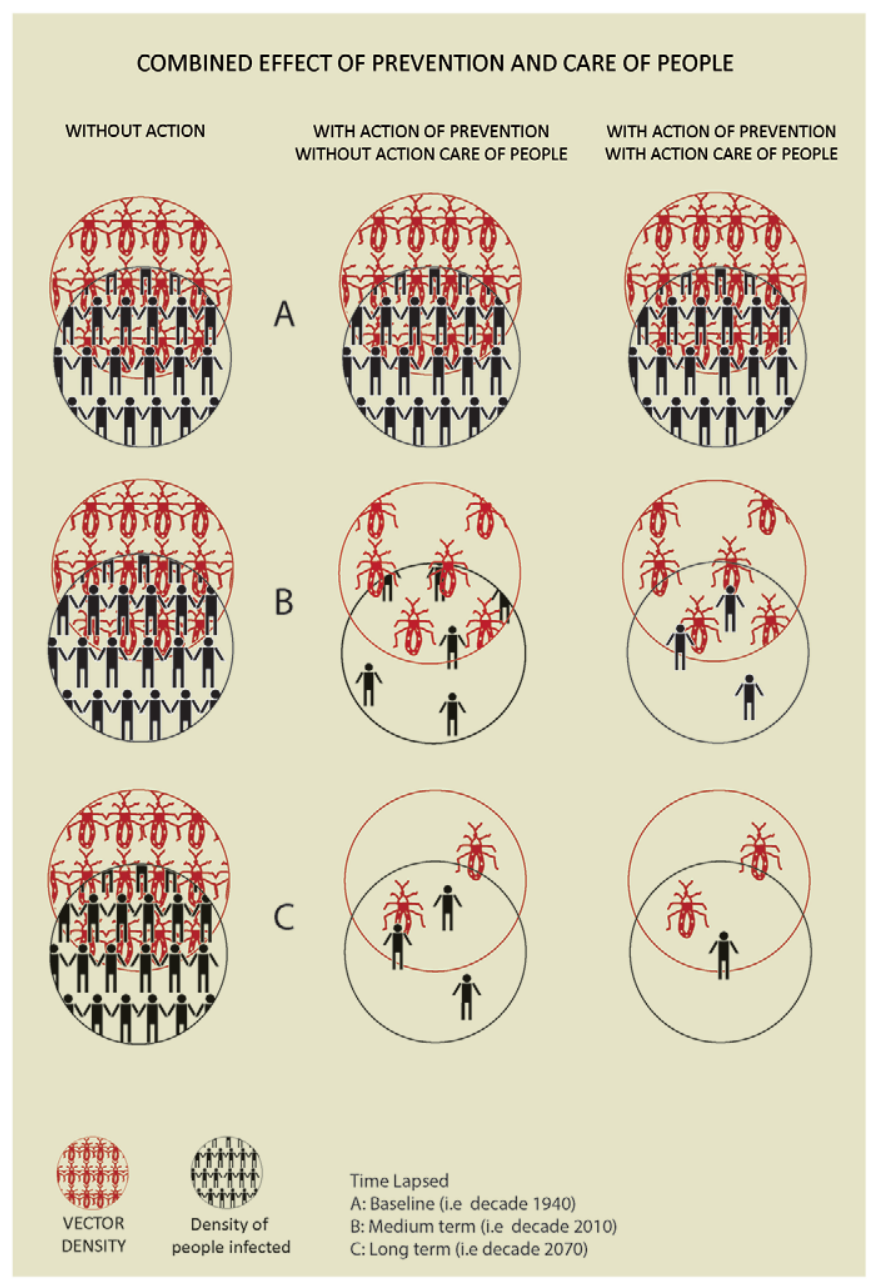

Fig. 3: combined effect of prevention and care for people in the control of Chagas disease.

ment can cure infection and reduce or prevent the progression of Chagas-related heart disease/cardiomyopathy. The current evidence of the benefits and limitations of etiological treatment based on clinical and implementation research help prioritise primary health care strategies, focusing on completing the course of treatment, rather than demonstrating serological negativisation.

Incorporating etiological treatment as a public health strategy useful at the primary, secondary and tertiary prevention levels is essential to reduce the burden of the disease and to eliminate Chagas disease as a public health issue.

There are guidelines advising regarding management and care of people infected with $T$. cruzi. A precocious and adequate clinical management is required to all acute or chronic cases. A timely and adequate clinical, pharmacological and chirurgical management if necessary is essential. The specific treatment has to be considered currently among other therapies (WHO 2002). For instance, timely management of initial arrhythmia, heart failure or megaesophagus is fundamental to avoid or delay the appearance of severe and irreversible situations, according several longitudinal studies have demonstrated (Viotti et al. 2005, Rassi Jr et al. 2006).
The medical care all over Latin America have different systems with subsystems and it must to have into account to resolve access to diagnosis and treatment, coverage, referential system, medical expertise, among others considerations. This is a new goal for an integrated Chagas disease control programs, including the care of people infected as formal objective and activities.

Control models and their effect - Based on the above, we can graph three intervention models and their expected effect on the evolution of the number of infected people.

The Fig. 3 defines three scenarios according to the intervention models and three times (baseline, medium and long term regarding time lapsed). These three scenarios are described just as a concept and not defined through a mathematical model. The first scenario where no intervention against the vector is carried out and vector transmission continues unabated generates an increase in the number of infected people. The second scenario is where only primary prevention actions are implemented, such as vector control and control of blood and organ donors. These actions achieve a progressive reduction of the number of infected people, but without 
care for infected people they remain infected for the rest of their lives; due to the phenomenon of population parasitaemia and migration, the risk of transmission by blood would increase. Finally, the third scenario considers primary prevention actions in conjunction with care of infected people, including etiological treatment. This combination can reduce the number of people infected with $T$. cruzi in a shorter time.

The implementation of actions with sufficient evidence of efficacy carried out in an integrated manner throughout the country is a challenge of political and technical decisionmaking. The proof of success in some communities should be a stimulus/incitation for communities with similar scenarios where these actions have not been implemented.

The field of research is oriented towards finding alternatives when the tools/strategies used stopped working or are unavailable. Thus, the research priorities for the present situation have been defined different in discussion forums, trying to find the best way of achieving an efficient implementation of control actions for the prevention of new cases and for taking care of those already infected (Dujardin et al. 2010).

Chagas disease cannot be eradicated due to the multiple scenarios that contribute to the occurrence of new cases and mainly because of the demonstrated existence of infected wild triatomines in permanent contact with domestic cycles. However, it is possible to interrupt the transmission of $T$. cruzi in a large territory, we have discussed before the complexity of dynamic of vector transmission to avoid new cases and having expectance to eradicate or eliminate this disease. Measures available of prevention of Chagas disease can reach high level of control due to total interruption of transmission by transfusion, total interruption of vector transmission in large areas and partial interruption or control in areas like Amazon Region and adequate level of coverage of timely diagnoses and treatment of people infected. The hypothesis is that in the future always will remain just few new cases, but the conjunction of the previous goal described will allow to eliminate Chagas disease as a public health problem. In this sense a cut-off point of magnitude of prevalence or incidences of people infected and its burden disease to decide when Chagas disease is not a public health problem has to be developed.

\section{REFERENCES}

Abad-Franch F, Vega MC, Rolón MS, Santos WS, de Arias AR 2011. Community participation in Chagas disease vector surveillance: systematic review. PLoS Negl Trop Dis 5: e1207.

Altclas J, Sinagra A, Dictar M, Luna C, Verón MT, de Rissio AM, García MM, Salgueira C, Riarte A 2005. Chagas disease in bone marrow transplantation: an approach to preemptive therapy. Bone Marrow Transplant 36: 123-129.

Bern C 2011. Antitrypanosomal therapy for chronic Chagas disease. N Engl J Med 364: 2527-2534.

Blanco SB, Segura EL, Cura EN, Chuit R, Tulián L, Flores I, Garbarino G, Villalonga JF, Gürtler RE 2000. Congenital transmission of Trypanosoma cruzi: an operational outline for detecting and treating infected infants in north-western Argentina. Trop Med Int Health 5: 293-301.
Bua J, Volta BJ, Velazquez EB, Ruiz AM, Rissio AM, Cardoni RL 2012. Vertical transmission of Trypanosoma cruzi infection: quantification of parasite burden in mothers and their children by parasite DNA amplification. Trans R Soc Trop Med Hyg 106: 623-628.

Carvalho ME, Silva RA, Wanderley DM, Barata JM 2011. Chagas Disease Control Program in the state of São Paulo, Brazil: serological and entomological aspects of primary school-children surveys. Rev Soc Bras Med Trop 44 (Suppl. 2): 95-106.

Ceballos LA, Piccinali RV, Marcet PL, Vazquez-Prokopec GM, Cardinal MV, Schachter-Broide J, Dujardin JP, Dotson EM, Kitron U, Gürtler RE 2011. Hidden sylvatic foci of the main vector of Chagas disease Triatoma infestans: threats to the vector elimination campaign? PLoS Negl Trop Dis 5: e1365.

Cerisola JA 1977. Chemotherapy of Chagas infection in man. In Chagas disease, Scientific Publication 347, Pan American Health Organization, Washington DC, p. 35-47.

Chuit R, Gurtler R, Mac Dougall L, Segura EL, Singer B 2001. Chagas disease - Risk assessment by an environmental approach in northern Argentina. Rev Patol Trop 30: 193-207.

Cordova E, Boschi A, Ambrosioni J, Cudos C, Corti M 2008. Reactivation of Chagas disease with central nervous system involvement in HIV-infected patients in Argentina, 1992-2007. Int J Infect Dis 12: 587-592.

de Oliveira Jr W 2006. Depressão e qualidade de vida no paciente chagásico. Rev Soc Bras Med Trop 39 (Suppl. 3): 130-132.

Dell'Arciprete A, Braunstein J, Touris C, Dinardi G, Llovet I, SosaEstani S 2014. Cultural barriers to effective communication between Indigenous communities and health care providers in northern Argentina: an anthropological contribution to Chagas disease prevention and control. Int J Equity Health 29: 6.

Dick OB, San Martín JL, Montoya RH, Del Diego J, Zambrano B, Dayan GH 2012. The history of dengue outbreaks in the Americas. Am J Trop Med Hyg 87: 584-593.

Diez M, Favaloro L, Bertolotti A, Burgos JM, Vigliano C, Lastra MP, Levin MJ, Arnedo A, Nagel C, Schijman AG, Favaloro RR 2007. Usefulness of PCR strategies for early diagnosis of Chagas disease reactivation and treatment follow-up in heart transplantation. Am J Transplant 7: 1633-1640.

Dujardin JC, Herrera S, do Rosario V, Arevalo J, Boelaert M, Carrasco HJ, Correa-Oliveira R, Garcia L, Gotuzzo E, Gyorkos TW, Kalergis AM, Kouri G, Larraga V, Lutumba P, Garcia MAM, Manrique-Saide PC, Modabber F, Nieto A, Pluschke G, Robello C, de Arias AR, Rumbo M, Preciado JIS, Sundar S, Torres J, Torrico F, Van der Stuyft P, Victoir K, Olesen OF 2010. Research priorities for neglected infectious diseases in Latin America and the Caribbean region. PLoS Negl Trop Dis 4: e780.

Fabbro DL, Danesi E, Olivera V, Codebó MO, Denner S, Heredia C, Streiger M, Sosa-Estani S 2014. Trypanocide treatment of women infected with Trypanosoma cruzi and its effect on preventing congenital Chagas. PLoS Negl Trop Dis 8: e3312.

Germano MD, Santo-Orihuela P, Roca-Acevedo G, Toloza AC, Vassena C, Picollo MI, Mougabure-Cueto G 2012. Scientific evidence of three different insecticide-resistant profiles in Triatoma infestans (Hemiptera: Reduviidae) populations from Argentina and Bolivia. J Med Entomol 49: 1355-1360.

Hanada K, Hashimoto K 2014. Buenas prácticas en el control de la enfermedad de Chagas en Centro América 2000-2014. Available from: libportal.jica.go.jp/fmi/xsl/library/public/ProjectHistory/ChagasDisease/CompletoBuenasPracticasChagasCAJICA2000-2014WEB.pdf.

Hashimoto K, Schofield CJ 2012. Elimination of Rhodnius prolixus in Central America. Parasit Vectors 5: 45. 
Herwaldt BL 2001. Laboratory-acquired parasitic infections from accidental exposures. Clin Microbiol Rev 14: 659-688.

Hotez PJ, Bottazzi ME, Franco-Paredes C, Ault SK, Periago MR 2008. The neglected tropical diseases of Latin America and the Caribbean: a review of disease burden and distribution and a roadmap for control and elimination. PLoS Negl Trop Dis 2: e300.

Howard EJ, Xiong X, Carlier Y, Sosa-Estani S, Buekens P 2014. Frequency of the congenital transmission of Trypanosoma cruzi: a systematic review and meta-analysis. BJOG 121: 22-33.

Lee BY, Bacon KM, Bottazzi ME, Hotez PJ 2013. Global economic burden of Chagas disease: a computational simulation model. Lancet Infect Dis 13: 342-348.

Mallimaci MC, Sijvarger C, Dates A, Alvarez M, Sosa-Estani S 2001. Seroprevalence of Chagas disease in Ushuaia, Argentina, an area without Triatominae. Rev Panam Salud Publica 9: 169-171.

Mallimaci MC, Sosa-Estani S, Russomando G, Sanchez Z, Sijvarger C, Alvarez IM, Barrionuevo L, Lopez C, Segura EL 2010. Early diagnosis of congenital Trypanosoma cruzi infection using shed acute phase antigen in Ushuaia, Tierra del Fuego, Argentina. $\mathrm{Am}$ $J$ Trop Med Hyg 82: 55-59.

Marin-Neto JA, Rassi Jr A, Morillo CA, Avezum A, Connolly SJ, Sosa-Estani S, Rosas F, Yusuf S, BENEFIT Investigators 2008. Rationale and design of a randomized placebo-controlled trial assessing the effects of etiologic treatment in Chagas' cardiomyopathy: the BENznidazole Evaluation for Interrupting Trypanosomiasis (BENEFIT). Am Heart J 156: 37-43.

Moya PR, Paolasso RD, Blanco S, Lapasset M, Sanmartino C, Basso B, Moretti E, Cura D 1985. Tratamiento de la enfermedad de Chagas con nifurtimox durante los primeros meses de vida. Medicina (B Aires) 45: 553-558.

MS - Ministerio de Salud 2012a. Guías para la atención al paciente infectado con Trypanosoma cruzi (Enfermedad de Chagas). Available from: msal.gov.ar/chagas/images/stories/Equipos/ Guia_Nacional_Chagas_version_27092012.pdf.

MS - Ministerio de Salud 2012b. Plan Nacional de Chagas 2011-2016, Resolución 867/2012-MS. Available from: msal.gov.ar/chagas/index.php/institucional/plan-nacional-de-chagas/lineas.

Nishioka S 2000. Benznidazol na quimioprofilaxia primária da reativação de doença de Chagas em chagásicos crônicos em uso de corticosteroides em doses imunodepressoras: há evidência suficiente para a recomendação do seu uso? Rev Soc Bras Med Trop 33: 83-85.

OPS - Organización Panamericana de la Salud 2002. El control de la enfermedad de Chagas en los países del Cono Sur de América. Historia de una iniciativa internacional: 1991-2001. Available from: paho.org/uru/index.php?option=com_docman\&task $=$ doc details\&gid $=54 \&$ Itemid $=241$.

OPS - Organización Panamericana de la Salud 2006. Estimación cuantitativa de la enfermedad de Chagas en las Américas, $\mathrm{PAHO} / \mathrm{WHO}$, Montevideo, $28 \mathrm{pp}$.

OPS - Organización Panamericana de la Salud 2009a. Eliminación de las enfermedades desatendidas y otras enfermedades transmisibles relacionadas con la pobreza. Available from: new.paho.org/ hq/dmdocuments/2009/01_Elimi_intro_junio_09.pdf.

OPS - Organización Panamericana de la Salud 2009b. Guía para vigilancia, prevención, control y manejo clínico de la enfermedad de Chagas aguda transmitida por alimentos, Serie de Manuales Técnicos 12, PANAFTOSA-VP/OPAS/OMS, Rio de Janeiro, 92 pp.

Pacheco-Tucuch FS, Ramirez-Sierra MJ, Gourbière S, Dumonteil E 2012. Public street lights increase house infestation by the Chagas disease vector Triatoma dimidiata. PLoS ONE 7: e36207.
Rassi Jr A, Rassi A, Little WC, Xavier SS, Rassi SG, Rassi AG, Rassi GG, Hasslocher-Moreno A, Sousa AS, Scanavacca MI 2006. Development and validation of a risk score for predicting death in Chagas' heart disease. N Engl J Med 355: 799-808.

Requena-Méndez A, Albajar-Viñas P, Angheben A, Chiodini P, Gascón J, Muñoz J, Chagas Disease COHEMI Working Group 2014. Health policies to control Chagas disease transmission in European countries. PLoS Negl Trop Dis 8: e3245.

Reyes PA, Vallejo M 2005. Trypanocidal drugs for late stage, symptomatic Chagas disease (Trypanosoma cruzi infection). Cochrane Database Syst Rev 4: CD004102.

Riarte A, Prado N, Luna C, Velázquez E, de Rissio AM, Malagrino N, Garcia MM, Hernández Y, Echeverri ME, Sinagra A, Laucella S, Esteve MI, Ruiz AM 2005. Tratamiento etiológico con benznidazol (BZ) en pacientes adultos en diferentes estadios de la enfermedad de Chagas crónica. Un ensayo clínico aleatorizado. Proceedings of the VII Congreso Argentino de Protozoología y Enfermedades Parasitarias, 2005 Sep, Mendoza, Argentina, Sociedad Argentina de Parasitología, Buenos Aires, p. 30-31.

Russomando G, de Tomassone MM, de Guillen I, Acosta N, Vera N, Almiron M, Candia N, Calcena MF, Figueredo A 1998. Treatment of congenital Chagas disease diagnosed and followed up by the polymerase chain reaction. Am J Trop Med Hyg 59: 487-491.

Schmunis GA, Cruz JR 2005. Safety of the blood supply in Latin America. Clin Microbiol Rev 18: 12-29. Erratum in Clin Microbiol Rev 18: 582.

Shikanai-Yasuda MA, Carvalho NB 2012. Oral transmission of Chagas disease. Clin Infect Dis 54: 845-852.

Silveira AC 2002. O controle da doença de Chagas nos países do Cone Sul da América. História de uma iniciativa internacional, 1991/2001. In AC Silveira, A Rojas de Arias, E Segura, G Guillén, G Russomando, H Schenone, JCP Dias, J Valdes, M Lorca, R Salvatella, El control de la enfermedad de Chagas en los paises del Cono Sur de América: historia de una iniciativa internacional, 1991/2001, Facultad de Medicina do Triangulo Mineiro, Uberaba, p. 15-43.

Sosa-Estani S 2012. El tratamiento etiológico de la enfermedad de Chagas como estrategia de salud pública. Rev Argent Salud Pública 11: 40-43.

Sosa-Estani S, Colantonio L, Segura EL 2012. Therapy of Chagas disease: implications for levels of prevention. J Trop Med 2012: 292138.

Sosa-Estani S, Dri L, Touris C, Abalde S, Dell'arciprete A, Braunstein J 2009a. Vectorial and congenital transmission of Trypanosoma cruzi in Las Lomitas, Formosa. Medicina (B Aires) 69: 424-430.

Sosa-Estani S, Viotti R, Segura EL 2009b. Therapy, diagnosis and prognosis of chronic Chagas disease: insight gained in Argentina. Mem Inst Oswaldo Cruz 104 (Suppl. I): 167-180.

Vazquez-Prokopec GM, Spillmann C, Zaidenberg M, Kitron U, Gürtler RE 2009. Cost-effectiveness of Chagas disease vector control strategies in northwestern Argentina. PLoS Negl Trop Dis 3: e363.

Villa L, Morote S, Bernal O, Bulla D, Albajar-Viñas P 2007. Access to diagnosis and treatment of Chagas disease/infection in endemic and non-endemic countries in the XXI century. Mem Inst Oswaldo Cruz 102 (Suppl. I): 87-94.

Viotti R, Alarcón de Noya B, Araújo-Jorge T, Grijalva MJ, Guhl F, López MC, Ramsey JM, Ribeiro I, Schijman AG, Sosa-Estani S, Torrico F, Gascon J, Latin American Network for Chagas Disease, NHEPACHA 2014. Towards a paradigm shift in the treatment of chronic Chagas disease. Antimicrob Agents Chemother 58: 635-639.

Viotti R, Vigliano C, Lococo B, Petti M, Bertocchi G, Álvarez MG, 
Armenti A 2005. Indicadores clínicos de progresión de la miocarditis chagásica crónica. Rev Esp Cardiol 58: 1037-1044.

WHO - World Health Organization 2002. Control of Chagas disease. Aetiological treatment. Tech Rep Ser 905: 1-109.

WHO - World Health Organization 2013. Sustaining the drive to overcome the global effect of neglected tropical diseases. Sec- ond WHO report on neglected tropical diseases. Available from: dropbox.com/sh/qct91n1cirqgnn1/FEnxDyk0hs?n=78824233.

Zingales B, Miles MA, Campbell DA, Tibayrenc M, Macedo AM, Teixeira MM, Schijman AG, Llewellyn MS, Lages-Silva E, Machado CR, Andrade SG, Sturm NR 2012. The revised Trypanosoma cruzi subspecific nomenclature: rationale, epidemiological relevance and research applications. Infect Genet Evol 12: 240-253. 